\title{
Endoscopic ultrasound-guided biliary drainage in high grade biliary hilar obstruction
}

Endoscopic ultrasound-guided biliary drainage (EUS-BD) is an effective and evolving modality. Biliary hilar strictures, however, cannot be optimally drained with EUS-BD while both endoscopic retrograde cholangiopancreatography (ERCP) and percutaneous drainage also have their limitations [1-3]. We describe a novel approach to EUS-BD in collaboration with interventional radiology, where hepaticogastrostomy (HPG) is performed with a bridging hilar stent to achieve optimal drainage in a BismuthCorlette type IV (BC-IV) obstruction ( $\triangleright$ Video 1).

A 62-year-old woman who had undergone radical cholecystectomy with duodenal resection and gastrojejunostomy for gallbladder cancer presented with symptoms suggestive of biliary obstruction. Computed tomography (CT) scan revealed a BC-IV hilar stricture due to tumor recurrence. Despite insertion of bilateral metal stents via the percutaneous route, the patient continued to have recurrent cholangitis due to rapid tumor stent ingrowth, leading to interruptions in chemotherapy treatment.

Following informed consent by the patient, a decision was made to undertake EUS-BD in collaboration with interventional radiology. Cholangiography via the percutaneous tube (PTBD) showed complete obstruction of both metal stents at the hilum due to tumor tissue ingrowth. A 0.035-inch guidewire was inserted, traversing the hilum through the stent indices and into segment III of the left intrahepatic biliary tree ( $\bullet$ Fig. 1 ). A transgastric puncture of this biliary segment was then performed with a 19-gauge needle under EUS guidance followed by the advancement of a 0.035 -inch guidewire antegradely. The wire was then captured via a snare inserted via the PTBD route and pulled through the percutaneous access. With optimal tension at both

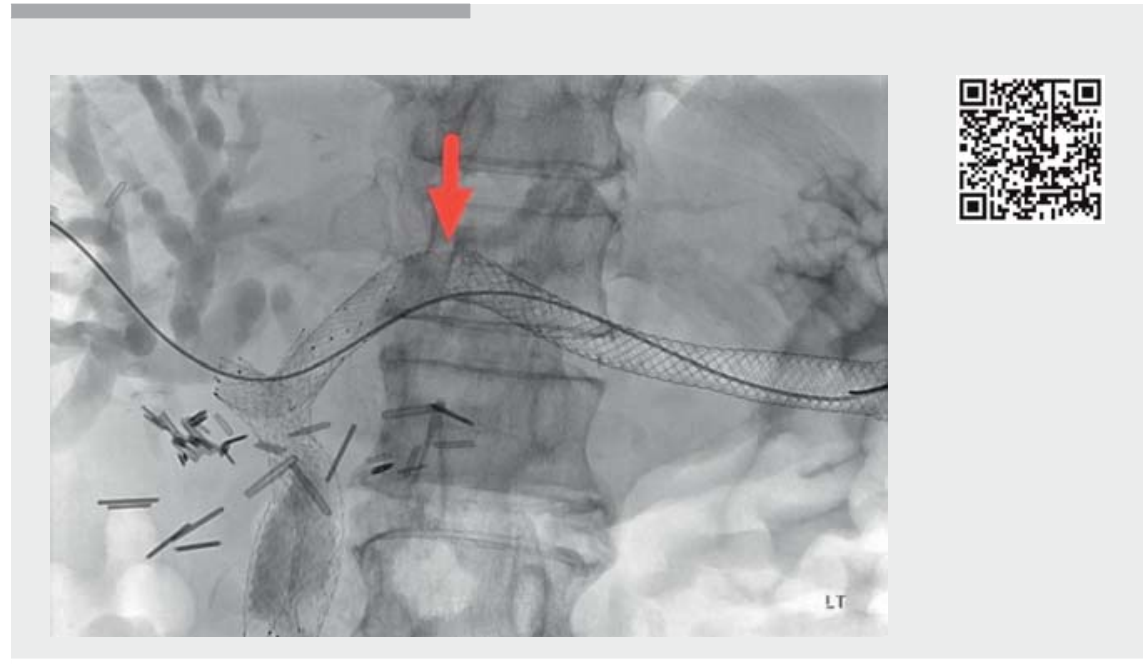

Video 1 Successful hepaticogastrostomy using endoscopic ultrasonography and interventional radiology for management of high grade hilar obstruction using a bridging stent technique. Sources for stents and scope pictures: Boston scientific and Pentax
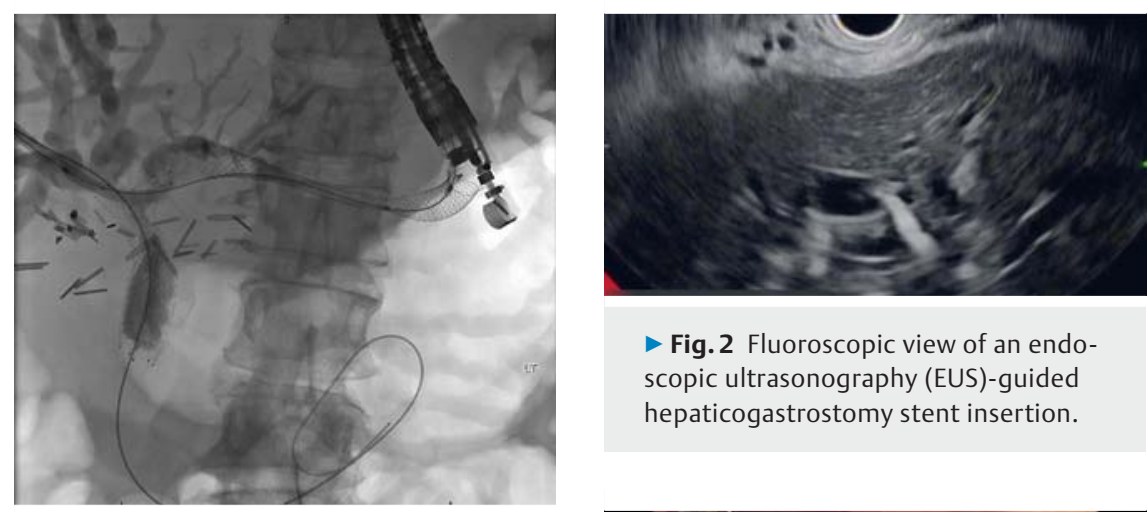

Fig. 2 Fluoroscopic view of an endoscopic ultrasonography (EUS)-guided hepaticogastrostomy stent insertion.

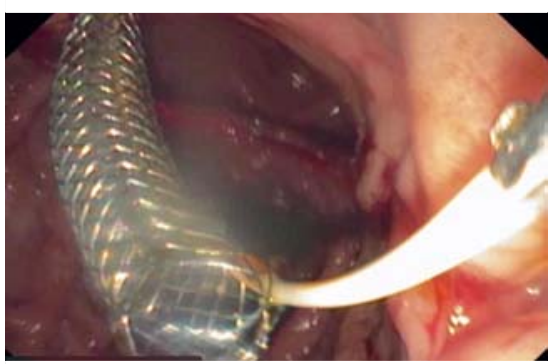

Fig. 3 Endoscopic view of an hepaticogastrostomy (HPG) stent. 


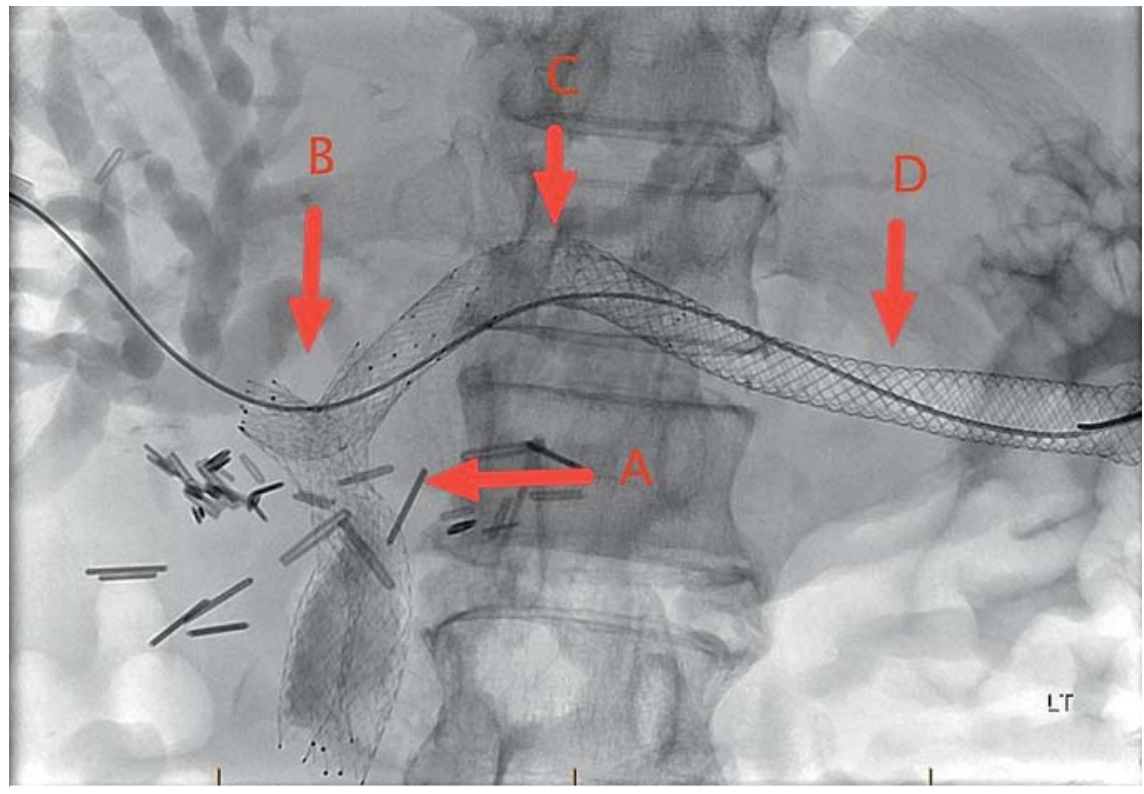

- Fig. 4 Fluoroscopic view of hepaticogastrostomy (HPG) stent and bridging stents. A, occluded previously placed hilar stents; B, $8-\mathrm{mm} \times 40-\mathrm{mm}$ balloon-expandable stent across the biliary bifurcation and hilar stricture; $C, 8-\mathrm{mm} \times 40$ - $\mathrm{mm}$ self-expandable stent placed between the HPG stent and biliary bifurcation stent; D, HPG stent.

taneously with deflation and pulling back of the dilating balloon, limiting the time between dilation and stent insertion and therefore the risk of bile leak ( $\boldsymbol{F}$ Fig. 2 and $>$ Fig. 3). Over the same guidewire, a bridging stent $(8-\mathrm{mm} \times 40-\mathrm{mm}$ balloonexpandable; Cordis) was then successfully deployed across the biliary bifurcation and hilar stricture. A second bridging stent $(8 \mathrm{~mm} \times 40 \mathrm{~mm}$ self-expandable; Cordis) was then placed between the HPG stent and biliary bifurcation stent ( $>$ Fig.4). A post-procedural cholangiogram confirmed complete drainage of the biliary system.

The patient did well after the procedure and at 4-month follow-up she showed no signs of biliary obstruction or cholangitis. In conclusion, a collaborative approach with interventional radiology can further extend the therapeutic indications for EUS-BD and allow successful establishment of stable biliary stents with optimal drainage in high grade hilar obstruction. Further studies are needed to assess safety.

Endoscopy_UCTN_Code_TTT_1AS_2AD
Corresponding author

\section{Yen-I Chen, MD}

Division of Gastroenterology and

Hepatology, McGill University Health Centre, 1001 Decarie Blvd, Montreal, Quebec,

H4A 3J1, Canada

Fax: (514)934-8547

yen-i.chen@mail.mcgill.ca

\section{References}

[1] Sharaiha RZ, Khan MA, Kamal F et al. Efficacy and safety of EUS-guided biliary drainage in comparison with percutaneous biliary drainage when ERCP fails: a systematic review and meta-analysis. Gastrointest Endosc 2017; 85: 904-914

[2] Al-Kawas F, Aslanian H, Baillie J et al. Percutaneous transhepatic vs. endoscopic retrograde biliary drainage for suspected malignant hilar obstruction: study protocol for a randomized controlled trial. Trials 2018; 19: 108

[3] Saluja SS, Gulati M, Garg PK et al. Endoscopic or percutaneous biliary drainage for gallbladder cancer: a randomized trial and quality of life assessment. Clin Gastroenterol Hepatol 2008; 6: 944-950, e3

Yen-I Chen is a consultant for Boston Scientific. David Valenti has been a speaker for Boston Scientific and Cook Medical. Alan Barkun has served as consultant for Cook, Pendopharm, and Olympus (also providing research support and serving on advisory committee) and received funds from Cook, Pendopharm, and Olympus. All other authors have no relevant conflicts of interest.

The authors

Ahmad Hashim ${ }^{1}$, Ali Bessissow², David Valenti ${ }^{2}$, Prosanto Chaudhury ${ }^{3}$, Alan Barkun ${ }^{1}$, Kevin Waschke ${ }^{1}$, Yen-I Chen ${ }^{1}$

1 Division of Gastroenterology and Hepatology, McGill University Health Center, Montreal, QC, Canada

2 Division of Interventional Radiology, McGill University Health Center, Montreal, QC, Canada

3 Department of Surgery, McGill University Health Center, Montreal, QC, Canada

\section{Bibliography}

DOI https://doi.org/10.1055/a-0836-2514

Published online: 23.5.2019

Endoscopy 2019; 51: E284-E285

(c) Georg Thieme Verlag KG

Stuttgart · New York

ISSN 0013-726X

\section{ENDOSCOPY E-VIDEOS}

https://eref.thieme.de/e-videos

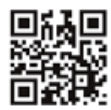

Endoscopy E-Videos is a free access online section, reporting on interesting cases and new techniques in gastroenterological endoscopy. All papers include a high quality video and all contributions are freely accessible online.

This section has its own submission website at https://mc.manuscriptcentral.com/e-videos 